one's living, the poorer food, the lack of pure air, the bustle and worry of life all conduce to the disease once more getting the mastery. 2. Early cases that might do permanently well too often leave the sanatorium after three months' treatment. I myself gave up a year to recovering and then only undertook light work, sacrificing prospects that had been very bright. I am quite convinced that otherwise a relapse would have occurred in my case also. During my first year's work after the illness, symptoms of malaise and loss of appetite would frequently occur. At these times I would resolutely eat full meals and rest in the open air almost entirely and would thus stave off the enemy. In ordinary life, with most of the working classes, this is impossible ; such patients expect to recover completely in three or four months and to remain well under most anfavourable conditions. 3. Consumption-after it has reached a stage which is recognisable by definite physical signs-is very rarely cured. Until better methods of treatment are discovered the most one can expect by sanatorium treatment (the best treatment at present known) is to build up the vitality of the patient with food, fresh air, and careful individual treatment. The disease thus is lessened in activity. If the vitality can be maintained the patient remains well but the disease is usually present though latent and awaiting its opportunity. I impress these views on all my patients. The truth, though disconcerting, makes them careful.

Now having briefly explained my own opinions on the above important points I will pass on to Dr. Macfie's article. He plainly states that sanatoriums can never be a great factor in eradicating consumption. He thinks they are of some use and that with a more careful selection of cases the use of sanatoriums would be doubled. I am so far in complete accordance. But until medical men as a class systematically look for consumption among their patients there will never be early cases enough to fill our present sanatoriums. Let all medical men carefully and systematically search for consumption in the following cases and they will often discover it much earlier than they may think. I refer to cases between 16 and 40 years of age who-(1) have "debility"; (2) have cough; (3) complain of fatigue; (4) complain of dyspepsia; (5) are pale ; (6) have had pleurisy (the majority of my patients have a history of pleurisy a few years previously); and (7) recover slowly after child-birth or any illness, such as influenza, \&c.

But even supposing we could fill our sanatoriums with early cases we cannot cure them, in my opinion. We can arrest the disease and the longer the disease remains arrested the more chance there is of permanent arrest. Colonies such as Dr. Macfie suggests might be of great use but $I$ am afraid that in the majority of instances early cases feeling well at the end of a few months at the sanatorium would refuse to stay a year or so at such colonies and these would then soon be filled with chronic cases of consumption. Dr. Macfie's example in support of his plea for such colonies is useless. Children are not wage earners; moreover, children can be controlled and kept at such colonies. Men and women feeling well would refuse to stay at a colony and run the risk of losing their situations from which probably they have only had three or at most six months' leave. Even when all their fees are paid by friends I often have difficulty in persuading such cases to stay more than three months. I therefore feel that colonies for consumptives will not be of much practical help and am of opinion that to get the greatest good out of sanatoriums, efforts should be made to get medical men to search for and to send early cases; and that these early cases should be enabled if possible to stay six months at a sanatorium. Sanatoriums will then be far more useful and less wasteful than under existing conditions. But they can never be of great use to the public-they will help individuals, but as a fartor towards the eradication of consumption, they are, and will be, failures.

We are "breeding" consumption too fast in our towns and insanitary dwelling houses to have any right to expect sanatoriums or any methods of treatment to prevail. Consumption must be prevented. By various sanitary improvements consumption is being gradually lessened but if there could only be a scientific and comprehensive attack on all the conditions predisposing to the disease what strides would be made! To sum up, sanatoriums with increased facilities for strict selection of suitable cases will be very useful institutions At present they are too costly through so mary beds being wasted in trying to treat hopeless cases. Colonies su sh as Dr. Macfie suggests may help but will be liable to the very same abuses which at present ruin the usefulness of sanatoriums. Better than anything, prevention must be our aim.--I am, Sirs, yours faithfully,

W. B. Herapath Wond, M.B. Lond. Medical Superintendent of the Liverpool Sanatorium.

Kingswood, Frodsham, Oct. 3rd, 1905.

\section{WEBSTER MEMORIAL HOSPITAL.}

\section{To the Editors of THE LANCET.}

SIrs, - In an article on the "Alverstone Memorial Hospital" in THE LANCET of Sept. 30th, p. 989, you state that the management of the hospital will rest in the hands of myself and my partner. Let me say that the management of the hospital is in the hands of a committee elected by the annual subscribers and further that the four medical men practising in Shanklin have been elected by the committee as an honorary medical staff to the hospital.

I am, Sirs, yours faithfully,

Shanklin, Isle of Wight, Oct. 7th, 1905. J. COWPER,

\section{CONGENITAL MULTIPLE OCCLUSIONS OF THE SMALE INTESTINE.}

To the Editors of THE LANOET.

SIRs,-In the interesting article on Congenital Multiple Occlusions of the Small Intestine published in THE LANCET of August 12th, p. 440, Dr. J. G. Emanuel states that he believes the case to be unique and has been unable to find the records of any similar case. I would draw his attention to a case operated upon by myself and published in the St. Thomas's Hospital Reports, vol. xxvi., new series for the year 1897. The report runs as follows : "Multiple congenital strictures of small intestine. E. H. P., male, æt. 3 days. Symptoms of obstruction since birth. Anus well formed. Rectum explored after removal of coccyx; no abnormality found. Abdomen opened in left iliac region, enormous coil of small gut presented. Stricture found and enterostomy performed just above stricture. Death from exhaustion the following day. P.M. Small gut for 12 inches below duodenum much distended and thickened. Five or six constrictions in remainder of small gut, each about one inch in length and impervious, as tested by forcing on bowel contents. The constricted parts of thickness of thin twine. Colon and rectum pervious, size of goose quill." Unfortunately I have no further notes of the case but to the best of my recollection there were no distended areas of small gut, except above the first stricture, as in Dr. Emanuel's case, but the contents of the gut were normal meconium. I am, Sirs, yours faithfully,

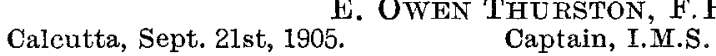

\section{THE CULTIVATION OF THE BACILIUS LEPR叛.}

To the Elitors of THE LANCET.

SIRS,-I noticed in THE LANCET of August 26th, p. 636, some notes on the supposed cure for leprosy put forward by Captain E. R. Rost, I.M.S. When Captain Rost's papers first appeared, although $I$ could not follow the reasons which led him to attempt to cultivate the bacillus lepræ in media free from sodium chloride, I wrote to India to procure 500 doses of the antisubstance because I did not wish to leave any remedy untried. At the same time I prepared media in strict accordance with Captain Rost's instructions and also with modifications. I obtained from the base of a leprotic nodule in a living subject a few minims of lymph full of the bacillus lepræ in pure culture. I inoculated many tubes of the different media and kept them for weeks in the incubator but they all remained sterile. Therefore, I was not surprised to receive a letter from India stating that as it had been demonstrated that the organism cultivated by Captain Rost was not the bacillus lepræ the manufacture of the remedy had been stopped. I gather from your notice that those who inquired into Captain Rost's method delivered themselves of some rather severe criticisms. This is a pity. Captain Rost is by no means the first man who has made a mistake with regard to the cultivation of the bacillus lepræ and probably he will not be the last. No doubt his failure is a great disappointment to him; it certainly is to me. It is 